\title{
LARGE-BASIS HARMONIC-OSCILLATOR SHELL MODEL APPLICATION TO ALPHA PARTICLE
}

\author{
D. Germanas ${ }^{\mathrm{a}}$, R.K. Kalinauskas ${ }^{\mathrm{a}}$, G.P. Kamuntavičius ${ }^{\mathrm{a}, \mathrm{b}}$, and R. Žemaičiūniené ${ }^{\mathrm{b}}$ \\ a Institute of Physics, Savanoriu 231, LT-02300 Vilnius, Lithuania \\ E-mail: kalinauskas@fi.lt \\ ${ }^{\mathrm{b}}$ Vytautas Magnus University, Donelaičio 58, LT-44029 Kaunas, Lithuania
}

Received 4 December 2003

\begin{abstract}
New calculations of the energy spectrum of the many-body nuclear Hamiltonian, evading the diagonalization of its matrix in an extremely large harmonic oscillator basis, are presented. The efficiency of this method, which is based on factorization of the antisymmetrizer and Hamiltonian operators, is compared to the direct one. The precision of the method is tested in four-body calculations using a modern realistic nucleon-nucleon potential.
\end{abstract}

Keywords: mathematical methods in physics, algebraic methods, nuclear shell model

PACS: 03.65.Fd, 21.60.Cs

\section{Introduction}

Recently, reliable calculations of light nuclei have been performed using high-precision nucleon-nucleon (NN) potentials [1-3]. The well-known methods (e.g., Hyperspherical Harmonics [4, 5]), as well as new methods (Faddeev-Yakubovski [6-8] and Green's Function Monte Carlo $[9,10])$ were employed, and the effective interactions in a truncated harmonic-oscillator basis [11-18] were also used. The last mentioned method is based on a previously developed technique of antisymmetrization of the translationally invariant harmonicoscillator basis [19] and on a procedure of diagonalization of the Hamiltonian matrix. Such technique [20,21] is essential as the limits of computer capabilities are reachable very quickly when huge matrices need to be diagonalized in order to get more or less acceptable results. Good results have been obtained using this method [22] for phenomenological effective interactions, but serious problems occur in the case when a bare $\mathrm{NN}$ potential is applied instead of effective interaction. The most important among them is very slow convergence of the process.

In our approach the structure of the Hamiltonian matrix is investigated and a way to evade direct calculation of big matrices is proposed. The matrix of the antisymmetrization operator as well as the matrix of the reduced Hamiltonian operator have been presented in the form of direct sums of simpler matrices. This op- eration, based on a simple basis modification, allows us to simplify the calculations and to make them faster. The precision of this method is compared with the results of earlier calculations.

\section{Bound state of the four-particle system}

We use the normalized Jacobi coordinate system, known as Jacobi tree, to ensure translational invariance of the many-body wave function. By definition, the Jacobi tree has $2 N-1$ vertices, $N$ of which are the vertices of the first order, see Fig. 1. They are arranged in a line and marked with the one-particle radius-vectors $\vec{r}_{1}, \vec{r}_{2}, \ldots, \vec{r}_{N}$. The order of remaining $N-1$ vertices

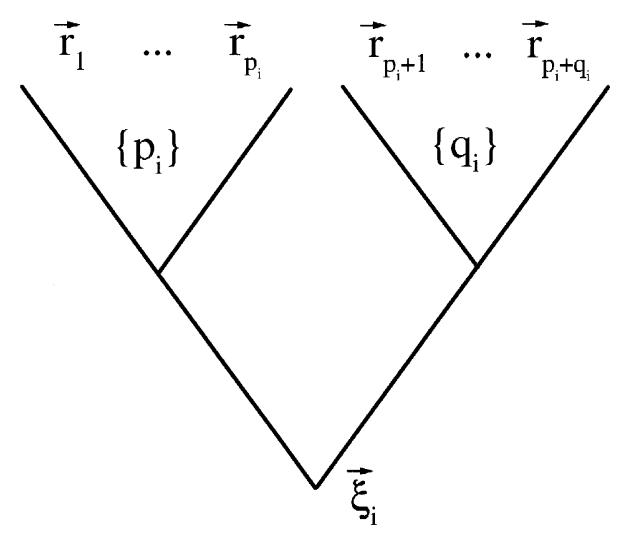

Fig. 1. The Jacobi tree sample. 


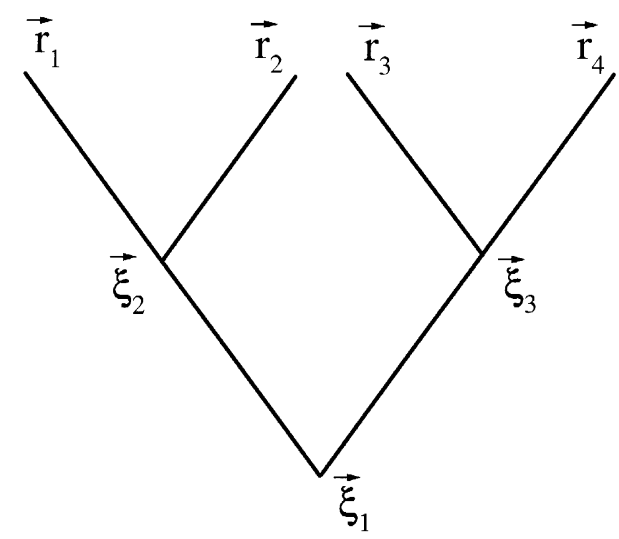

Fig. 2. The Jacobi tree for the four particles.

situated below the first group is 2 or 3 . These vertices are labelled $1,2, \ldots, N-1$, where the numbers correspond to Jacobi coordinates given by the formula

$$
\vec{\xi}_{i}=\sqrt{\frac{p_{i} q_{i}}{p_{i}+q_{i}}}\left[\frac{1}{p_{i}} \sum_{j \in\left\{p_{i}\right\}} \vec{r}_{j}-\frac{1}{q_{i}} \sum_{j \in\left\{q_{i}\right\}} \vec{r}_{j}\right],
$$

and $p_{i}$ is the number of the first-order vertices to the left of the $i$ th Jacobi coordinate, $\left\{p_{i}\right\}$ is a set of its indices. $q_{i}$ and $\left\{q_{i}\right\}$ mean the same for the right side. This system of coordinates is very useful, because if the centre-of-mass coordinate is defined as

$$
\vec{\xi}_{0}=\frac{1}{\sqrt{N}} \sum_{j=1}^{N} \vec{r}_{j}
$$

then the transformation matrix between the sets $\vec{r}_{1}, \vec{r}_{2}, \ldots, \vec{r}_{N}$ and $\vec{\xi}_{0}, \vec{\xi}_{1}, \ldots, \vec{\xi}_{N}$ (as well as between all Jacobi coordinate systems) is orthogonal. All Jacobi coordinates should have the corresponding spin and isospin coordinates, $\sigma_{i}$ and $\tau_{i}$, respectively. The number of the spin-isospin variables associated with a vertex corresponding to a definite Jacobi coordinate equals the number of vertices of the first order that are directly connected to the given vertex. Now let us choose the Jacobi coordinates for the four-particle system to be as follows [23] (see Fig. 2):

$$
\begin{aligned}
& \vec{\xi}_{1}=\frac{1}{2}\left(\vec{r}_{1}+\vec{r}_{2}-\vec{r}_{3}-\vec{r}_{4}\right), \\
& \vec{\xi}_{2}=\frac{1}{\sqrt{2}}\left(\vec{r}_{1}-\vec{r}_{2}\right), \\
& \vec{\xi}_{3}=\frac{1}{\sqrt{2}}\left(\vec{r}_{3}-\vec{r}_{4}\right) .
\end{aligned}
$$

The spin-isospin coordinates assigned to $\vec{\xi}_{2}$ and $\vec{\xi}_{3}$ are $\sigma_{1} \tau_{1} \sigma_{2} \tau_{2}$ and $\sigma_{3} \tau_{3} \sigma_{4} \tau_{4}$, respectively [23]. The corresponding basis functions are labelled as follows:

$$
\begin{aligned}
\Phi_{e_{2} l_{2} s_{2} j_{2} m_{2} t_{2} m_{t_{2}}}\left(\vec{\xi}_{2} \sigma_{1} \tau_{1} \sigma_{2} \tau_{2}\right) \\
=\left\{\Phi_{e_{2} l_{2}}\left(\vec{\xi}_{2}\right)\left[\alpha_{1 / 2}\left(\sigma_{1}\right) \alpha_{1 / 2}\left(\sigma_{2}\right)\right]_{s_{2}}\right\}_{j_{2} m_{2}} \\
\quad \times\left[\alpha_{1 / 2}\left(\tau_{1}\right) \alpha_{1 / 2}\left(\tau_{2}\right)\right]_{t_{2} m_{t_{2}}},
\end{aligned}
$$

and

$$
\begin{aligned}
\Phi_{e_{3} l_{3} j_{3} m_{3} m_{t_{3}}}\left(\vec{\xi}_{3} \sigma_{3} \tau_{3} \sigma_{4} \tau_{4}\right) \\
=\left\{\Phi_{e_{3} l_{3}}\left(\vec{\xi}_{3}\right)\left[\alpha_{1 / 2}\left(\sigma_{3}\right) \alpha_{1 / 2}\left(\sigma_{4}\right)\right]_{s_{3}}\right\}_{j_{3} m_{3}} \\
\quad \times\left[\alpha_{1 / 2}\left(\tau_{3}\right) \alpha_{1 / 2}\left(\tau_{4}\right)\right]_{t_{3} m_{t_{3}}},
\end{aligned}
$$

where $e_{2}, l_{2}, s_{2}, j_{2}$, and $t_{2}$ are the oscillator excitation energy, angular momentum, spin, total momentum, and isospin of the first two particles, and $e_{3}, l_{3}$, $s_{3}, j_{3}$, and $t_{3}$ are the oscillator excitation energy, angular momentum, spin, total momentum, and isospin of the last two particles. We use the components of the four-body wave functions that are antisymmetric only with respect to the first two and the last two particles:

$$
\begin{aligned}
& \Phi_{J^{\pi} T M M_{T}}(1,2 ; 3,4)
\end{aligned}
$$

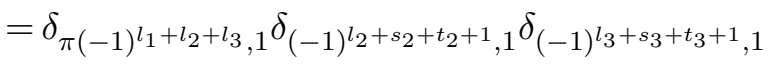

$$
\begin{aligned}
& \times \sum_{e_{1} l_{1} e_{2} l_{2} s_{2} j_{2} t_{2} j_{12} e_{3} l_{3} s_{3} j_{3} t_{3}} a_{e_{1} l_{1} e_{2} l_{2} s_{2} j_{2} t_{2} j_{12} e_{3} l_{3} s_{3} j_{3} t_{3}}^{\pi^{\pi} T} \\
& \times\left\{\left[\Phi_{e_{1} l_{1}}\left(\vec{\xi}_{1}\right) \Phi_{e_{2} l_{2} s_{2} j_{2} t_{2}}\left(\vec{\xi}_{2} \sigma_{1} \tau_{1} \sigma_{2} \tau_{2}\right)\right]_{j_{12}}\right. \\
& \left.\times \Phi_{e_{3} l_{3} s_{3} j_{3} t_{3}}\left(\vec{\xi}_{3} \sigma_{3} \tau_{3} \sigma_{4} \tau_{4}\right)\right\}_{J M T M_{T}},
\end{aligned}
$$

and $e_{1}, l_{1}$ are the oscillator excitation energy and the angular momentum of relative motion of the two subclusters.

The functional differential equation of [23] for this component is

$$
H_{3,4} X_{1,2 ; 3,4} \Phi(1,2 ; 3,4)=E \Phi(1,2 ; 3,4) .
$$

We solve this equation using a basis of harmonicoscillator functions having dimensionless coordinates $\vec{\xi}_{1} / b, \vec{\xi}_{2} / b, \vec{\xi}_{3} / b$, and the oscillator length parameter $b^{2}=\hbar /(m \omega)$. For ${ }^{4} \mathrm{He}$ the mass of the nucleon equals 
$\left(m_{p}+m_{n}\right) / 2$, see [24]. The reduced Hamiltonian operator is

$$
H_{3,4}=6 \hbar \omega\left(-\frac{1}{4} \Delta_{\xi_{3}}+\frac{V\left(\sqrt{2} b \vec{\xi}_{3}, \sigma_{3} \tau_{3} \sigma_{4} \tau_{4}\right)}{\hbar \omega}\right),
$$

and for simplicity its dimensionless form $h_{3,4}=$ $H_{3,4} /(6 \hbar \omega)$ will be used hereinafter. The antisymmetrizer for the four-particle system can be represented in the form

$$
A_{1,2,3,4}=\frac{1}{3}\left(1-P_{13}-P_{14}\right) \frac{1}{2}\left(1+P_{13} P_{24}\right) A_{1,2} A_{3,4},
$$

where $A_{1,2}$ and $A_{3,4}$ are antisymmetrizers for twoparticle subclusters. We can simplify the reduced Hamiltonian, employing a basis of harmonic-oscillator functions for computing its matrix element:

$$
\begin{aligned}
\left\langle\left(\left((e l)_{1},(e l s j t)_{2}\right) j_{12} ;(e l s j t)_{3}\right) E J M T M_{T}\right| h_{3,4} \\
\times \mid\left(\left((e l)_{1}^{\prime},(e l s j t)_{2}^{\prime}\right) j_{12}^{\prime} ;\right. \\
\left.\left.\quad(e l s j t)_{3}^{\prime}\right) E^{\prime} J^{\prime} M^{\prime} T^{\prime} M_{T^{\prime}}\right\rangle \\
=\delta_{\left(J M T M_{T}\right),\left(J M T M_{T}\right)^{\prime}} \delta_{(e l)_{1},(e l)_{1}^{\prime}} \delta_{(e l s j t)_{2},(e l s j t)_{2}^{\prime}} \\
\times \delta_{j_{12}, j_{12}^{\prime}} \delta_{(s j t)_{3},(s j t)_{3}^{\prime}} h_{e_{3} l_{3}, e_{3}^{\prime} l_{3}^{\prime}}^{j_{3} \pi_{3} t_{3}}
\end{aligned}
$$

Let us now transform the operator $h_{3,4}$ into the form

$$
\begin{aligned}
h_{3,4} & =-\frac{1}{4} \Delta_{\xi_{3}}+V_{3,4} \\
& =-\frac{1}{4} \Delta_{\xi_{3}}+\frac{1}{4} \xi_{3}^{2}+V_{3,4}-\frac{1}{4} \xi_{3}^{2} \\
& =\frac{1}{2}\left[\frac{1}{2}\left(-\Delta_{\xi_{3}}+\xi_{3}^{2}\right)\right]+\left[V_{3,4}-\frac{1}{4} \xi_{3}^{2}\right],
\end{aligned}
$$

thereby yielding the following expression for the matrix element in Eq. (12):

$$
\begin{aligned}
h_{e_{3} l_{3}, e_{3}^{\prime} l_{3}^{\prime}}^{j_{3}^{\pi_{3}} t_{3}}= & \frac{1}{2}\left(e_{3}+\frac{3}{2}\right) \delta_{e_{3} l_{3}, e_{3}^{\prime} l_{3}^{\prime}} \\
& +V\left(\sqrt{2} b \vec{\xi}_{3}\right)-\frac{1}{4}\left(\xi_{3}^{2}\right)_{e_{3} l_{3}, e_{3}^{\prime} l_{3}^{\prime}} .
\end{aligned}
$$

Due to antisymmetry with respect to permutations $1 \Leftrightarrow 2$ and $3 \Leftrightarrow 4$ of particles in subclusters, the matrix elements of the antisymmetrizer can be evaluated as matrix elements of a simpler operator

$$
X=\frac{1}{6}\left(1-2 P_{24}\right)\left(1+P_{13} P_{24}\right) .
$$

The matrix element of the operator $P_{24}$, essential in Eq. (15), is given by

$$
\begin{aligned}
& \left\langle\left(\left((e l)_{1},(\text { elsjt })_{2}\right) j_{12} ;(\text { elsjt })_{3}\right) E J T\right| P_{24} \\
& \left.\times \mid\left(\left((e l)_{1}^{\prime},(\text { elsjt })_{2}^{\prime}\right) j_{12}^{\prime} ;(\text { elsjt })_{3}^{\prime}\right) E J T\right\rangle \\
& =(-1)^{j_{2}+j_{2}^{\prime}+l_{3}+l_{3}^{\prime}+j_{3}+j_{3}^{\prime}} \\
& \times\left[s_{2}, t_{2}, j_{2}, j_{12}, s_{3}, t_{3}, j_{3},\right. \\
& \left.s_{2}^{\prime}, t_{2}^{\prime}, j_{2}^{\prime}, j_{12}^{\prime}, s_{3}^{\prime}, t_{3}^{\prime}, j_{3}^{\prime}\right]^{1 / 2} \\
& \times\left\{\begin{array}{ccc}
\frac{1}{2} & \frac{1}{2} t_{2} \\
\frac{1}{2} & \frac{1}{2} t_{3} \\
t_{2}^{\prime} & t_{3}^{\prime} T
\end{array}\right\} \sum_{\bar{j}, \overline{\bar{j}}}[\bar{j}, \overline{\bar{j}}]\left\{\begin{array}{lll}
l_{1} & j_{2} & j_{12} \\
j_{3} & J & \overline{\bar{j}}
\end{array}\right\}\left\{\begin{array}{lll}
l_{1}^{\prime} & j_{2}^{\prime} & j_{12}^{\prime} \\
j_{3}^{\prime} & J & \bar{j}
\end{array}\right\} \\
& \times \sum_{\bar{e}, \bar{l}, L, \bar{L}, S}(-1)^{L+\bar{L}}[L, \bar{L}, S]\left\{\begin{array}{ccc}
\frac{1}{2} & \frac{1}{2} & s_{2} \\
\frac{1}{2} & \frac{1}{2} & s_{3} \\
s_{2}^{\prime} & s_{3}^{\prime} & S
\end{array}\right\} \\
& \times\left\langle\bar{e} \bar{l}, e_{1} l_{1}: L \mid e_{2}^{\prime} l_{2}^{\prime}, e_{3}^{\prime} l_{3}^{\prime}: L\right\rangle_{1} \\
& \times\left\langle e_{2} l_{2}, e_{3} l_{3}: \bar{L} \mid \bar{e} \bar{l}, e_{1}^{\prime} l_{1}^{\prime}: \bar{L}\right\rangle_{1}
\end{aligned}
$$

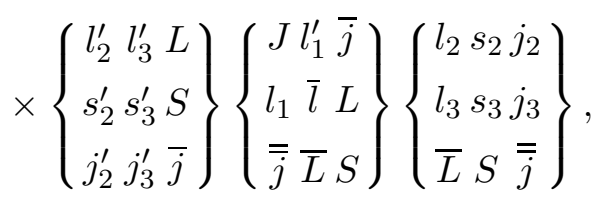

where $[a, b, \ldots]$ is shorthand notation for $(2 a+1) \times$ $(2 b+1) \cdots$. The $\left\langle E L, e l: \Lambda \mid e_{1} l_{1}, e_{2} l_{2}: \Lambda\right\rangle_{d}$ is a general harmonic-oscillator bracket, as defined in [25].

\section{Hermitization}

The operators $\mathbf{H}$ and $\mathbf{X}$ in Eq. (9) are Hermitian, i. e.

$$
\mathbf{H}=\mathbf{H}^{+}, \quad \mathbf{X}=\mathbf{X}^{+} ;
$$

however, the product $\mathbf{H X}$ is obviously not a Hermitian operator, because

$$
(\mathbf{H X})^{+}=\mathbf{X H} \neq \mathbf{H X} .
$$

This complicates the problem, but we have found at least two ways to make this operator Hermitian. The first method is based on the spectral decomposition of the matrix $\mathbf{X}_{n \times n}$ :

$$
\mathbf{X}=\mathbf{F F}^{+},
$$


where the matrix $\mathbf{F}_{n \times r}$ contains $r=\operatorname{Sp} \mathbf{X}$ linearly independent columns. Rewriting the functional differential equation as

$$
\mathbf{H F F}^{+} \Phi=\Phi E,
$$

we can multiply then Eq. (20) on the left by $\mathbf{F}^{+}$to obtain

$$
\mathbf{F}^{+} \mathbf{H F F}^{+} \Phi=\mathbf{F}^{+} \Phi E .
$$

The matrix

$$
\left(\mathbf{F}^{+} \mathbf{H F}\right)^{+}=\mathbf{F}^{+} \mathbf{H F}
$$

is Hermitian. The second method is even simpler. The matrix $\mathbf{X}$ is a projection matrix, so

$$
\mathbf{X X}=\mathbf{X}
$$

Rewriting Eq. (9) as

$$
\mathbf{X H X X} \Phi=E \mathbf{X} \Phi,
$$

we obtain a Hermitian matrix, because

$$
(\mathbf{X H X})^{+}=\mathbf{X H X} \text {. }
$$

This $n \times n$ matrix has only $r$ physical eigenvalues that are not identically equal to zero. These redundant solutions are spurious, but all of them correspond to eigenvalues $E \equiv 0$, hence one has no problems with them, because bound states and spurious states are well separated.

\section{Structure of matrices}

The matrix $\mathbf{X}$ has a well-defined structure depending on the harmonic-oscillator energy quantum number $E=e_{1}+e_{2}=0,2,4, \ldots$ It splits into submatrices $\mathbf{X}(E)$ corresponding to different values of $E$ :

$$
\mathbf{X}=\mathbf{X}(0) \oplus \mathbf{X}(2) \oplus \mathbf{X}(4) \oplus \cdots,
$$

i. e. it is diagonal with respect to the oscillator energy $E$, while all the off-diagonal matrix elements are identically zeroes and need not be kept in memory.

As one sees from the previous definition, the matrix $\mathbf{X}$, as well as its submatrices corresponding to different values of $E$, is a projection operator and possesses the properties

$$
\mathbf{X}(E) \mathbf{X}(E)=\mathbf{X}(E), \quad \mathbf{X}^{+}(E)=\mathbf{X}(E) .
$$

The matrix $\mathbf{F}$ is obtained from $\mathbf{X}$ as follows: the submatrices of $\mathbf{X}$ corresponding to different values of $E$ are diagonalized, and the matrices of eigenvectors corresponding to the eigenvalues 1 are calculated. A direct sum of matrices of the eigenvectors corresponding
Table $1 .{ }^{4} \mathrm{He}$ binding energy calculations.

\begin{tabular}{rrccrr}
\hline$N$ & \multicolumn{1}{c}{$d$} & $f$ & $n$ & \multicolumn{1}{c}{$t$} & \multicolumn{1}{c}{$E$} \\
\hline 0 & 2 & 2 & 2 & 0.11 & 617.83 \\
2 & 19 & 70 & 27 & 0.37 & 230.11 \\
4 & 93 & $1.1 \cdot 10^{3}$ & 171 & 1.10 & 92.60 \\
6 & 321 & $1.1 \cdot 10^{4}$ & 729 & 4.23 & 33.55 \\
8 & 889 & $6.9 \cdot 10^{4}$ & $2.4 \cdot 10^{3}$ & 24 & 6.38 \\
10 & 2114 & $3.3 \cdot 10^{5}$ & $6.6 \cdot 10^{3}$ & 148 & -5.82 \\
12 & 4494 & $1.3 \cdot 10^{6}$ & $1.6 \cdot 10^{4}$ & 1033 & -14.06 \\
14 & 8766 & $4.4 \cdot 10^{6}$ & $3.5 \cdot 10^{4}$ & 5849 & -18.45 \\
16 & 15972 & $1.3 \cdot 10^{7}$ & $7.1 \cdot 10^{4}$ & 29006 & -21.32 \\
\hline
\end{tabular}

to different values of $E$, as in the structure of $\mathbf{X}$, yields the matrix $\mathbf{F}$.

The matrix of the reduced Hamiltonian has a similar structure, i.e. it splits into a direct sum of diagonal submatrices labelled by the quantum numbers of the nucleon-nucleon channel $j_{2}^{\pi_{2}} t_{2}$.

Finally, the matrix of the reduced Hamiltonian can be written in the form

$$
\mathbf{H}=\mathbf{H}\left(j_{2}^{\pi_{2}} t_{2}=0^{+} 1\right) \oplus \mathbf{H}\left(j_{2}^{\pi_{2}} t_{2}=1^{+} 0\right) \oplus \cdots .
$$

\section{Calculations}

To illustrate the efficiency of Eq. (9) in solving matrix diagonalizations, we have performed the ${ }^{4} \mathrm{He}$ binding energy calculations based on the block structure of $\mathbf{F}$ and $\mathbf{H}$ matrices. Only the upper or the lower triangle of nonzero submatrices with diagonal elements included have to be filled in and kept in memory.

In summary, we have to:

(i) calculate the matrix $\mathbf{F}$,

(ii) calculate the matrix $\mathbf{H}$,

(iii) find the expression $\mathbf{F}^{+} \mathbf{H F}$,

(iv) find several low-lying eigenvalues and corresponding eigenvectors of this matrix.

The results of our calculations are presented in Table 1 in the following order: the oscillator excitation quanta $N$, the number of states $d$ in our basis, the number of elements $f$ in the array $\mathbf{F}$, the number of elements $n$ in the array $\mathbf{H}$, the calculation time $t$ in seconds, and the last parameter is the ${ }^{4} \mathrm{He}$ binding energy $E$.

As an illustration of efficiency of the applied method, one can mention that for the number of oscillator quanta $N$ equal to 16 the number of elements in the matrices $\mathbf{X}$ or $\mathbf{H}$ is $2.6 \cdot 10^{8}$, while applying our modification the number of elements in the array $\mathbf{F}$ is $1.3 \cdot 10^{7}$, and the number of elements in the array $\mathbf{H}$ is only $7 \cdot 1 \cdot 10^{4}$. According to this we need much less 
floating-point operations to perform calculations. The known result of exact calculation for binding energy of the $\alpha$-particle with a realistic NN potential is equal to $-24.25 \mathrm{MeV}$ [27].

Our calculations were performed on the ALPHA $1000 \mathrm{MHz} 1 \mathrm{~GB}$ computer using the realistic nucleonnucleon potential Reid93 [1]. The value of the oscillator parameter $b=0.73 \mathrm{fm}$ was chosen so that the binding energy would be minimal. When the number of the oscillator quanta is high, the binding energy depends only slightly on the parameter $b$.

\section{References}

[1] V.G.J. Stoks, R.A.M. Klomp, C.P.F. Terheggen, and J.J. de Swart, Phys. Rev. C 49, 2950 (1994).

[2] R.B. Wiringa, V.G.J. Stoks, and R. Schiavilla, Phys. Rev. C 51, 38 (1995).

[3] R. Machleidt, F. Sammarruca, and Y. Song, Phys. Rev. C 53, 1483 (1996).

[4] M. Viviani, A. Kievsky, and S. Rosati, Few-Body Syst. 18, 25 (1995).

[5] N. Barnea, W. Leidemann, and G. Orlandini, Nucl. Phys. A 650, 427 (1999).

[6] W. Glockle and H. Kamada, Phys. Rev. Lett. 71, 971 (1993).

[7] F. Cieselski and J. Carbonell, Phys. Rev. C 58, 58 (1998).

[8] F. Cieselski, J. Carbonell, and C. Gignoux, Nucl. Phys. A 631, 653 (1998).

[9] B.S. Pudliner, V.R. Pandharipande, J. Carlson, S.C. Pieper, and R.B. Wiringa, Phys. Rev. C 56, 1720 (1997).

[10] R.B. Wiringa, Nucl. Phys. A 631, 70 (1998).

[11] D.C. Zheng, B.R. Barrett, L. Jaqua, J.P. Vary, and R.J. McCarthy, Phys. Rev. C 48, 1083 (1993).
[12] D.C. Zheng, J.P. Vary, and B.R. Barrett, Phys. Rev. C 50, 2841 (1994).

[13] D.C. Zheng, B.R. Barrett, J.P. Vary, W.C. Haxton, and C.-L. Song, Phys. Rev. C 52, 2488 (1995).

[14] P. Navratil and B.R. Barrett, Phys. Rev. C 54, 2986 (1996).

[15] P. Navratil and B.R. Barrett, Phys. Rev. C 57, 562 (1998).

[16] P. Navratil and B.R. Barrett, Phys. Rev. C 57, 3119 (1998).

[17] P. Navratil and B.R. Barrett, Phys. Rev. C 59, 1906 (1999).

[18] H. Kamada, A. Nogga, W. Glöckle, E. Hiyama, M. Kamimura, K. Varga, Y. Suzuki, M. Viviani, A. Kievsky, S. Rosati, J. Carlson, Steven C. Pieper, R.B. Wiringa, P. Navratil, B.R. Barrett, N. Barnea, W. Leidemann, and G. Orlandini, Phys. Rev. C 64, 044001 (2001).

[19] G.P. Kamuntavičius, Fiz. Elem. Chast. At. Yadra 20, 261 (1989) [Sov. J. Part. Nucl. 20, 109 (1989)].

[20] D. Germanas, G.P. Kamuntavičius, and R.K. Kalinauskas, Lithuanian J. Phys. 41(3), 200-203 (2001).

[21] G.P. Kamuntavičius, D. Germanas, R.K. Kalinauskas, and R. Žemaičiūnienè, Lithuanian J. Phys. 43(2), 81-88 (2003).

[22] P. Navratil, G.P. Kamuntavičius, and B.R. Barrett, Phys. Rev. C 61, 044001 (2000).

[23] G.P. Kamuntavičius, Few-Body Syst. 1, 91 (1986).

[24] G.P. Kamuntavičius, P. Navratil, B.R. Barrett, G. Sapragonaite, and R.K. Kalinauskas, Phys. Rev. C 60, 044304 (1999).

[25] G.P. Kamuntavičius, R.K. Kalinauskas, B.R. Barrett, S. Mickevičius, and D. Germanas, Nucl. Phys. A 695, 191 (2001).

[26] J.L. Friar, G.L. Payne, V.G.J. Stoks, and J.J. de Swart, Phys. Lett. B 311, 4 (1993).

[27] A. Nogga, H. Kamada, W. Glöckle, and B.R. Barrett, Phys. Rev. C 65, 054003 (2002). 


\title{
LABAI PLAČIOS BAZĖS HARMONINIO OSCILIATORIAUS SLUOKSNIŲ MODELIO TAIKYMAS ALFA DALELEI
}

\author{
D. Germanas ${ }^{\text {a }}$, R.K. Kalinauskas ${ }^{\text {a }}$, G.P. Kamuntavičius ${ }^{\text {a }}$ b, R. Žemaičiūniené ${ }^{b}$ \\ ${ }^{a}$ Fizikos institutas, Vilnius, Lietuva \\ ${ }^{\mathrm{b}}$ Vytauto Didžiojo universitetas, Kaunas, Lietuva
}

\section{Santrauka}

Pagrindinè branduolio sandaros fizikos problema yra branduolio savybiu apskaičiavimas, remiantis naujausiais aukštos kokybès tarpnukleoninès sąveikos realistiniais potencialais. Taip skaičiuoti šiuo metu i̇manoma tik lengvuosius branduolius hipersferinių harmoniku, Fadejevo ir Jakubovskio, Green'o funkcijos Monte Carlo metodais arba naudojant efektyvines sąveikas sluoksninio modelio harmoninio osciliatoriaus antisimetrinių, transliaciniai invariantiniu būsenų bazejje. Pastarasis metodas yra gerai išplètotas, ir ji naudojant gaunami neblogi rezultatai, nagrinèjant fe- nomenologines efektyvines sąveikas. Tačiau nagrinėjant realistinius tarpnukleoninès sąveikos potencialus, konvergavimas yra labai lètas, branduolio hamiltoniano matricos eilè greitai dideja, ir jai diagonalizuoti nepakanka ir galingiausiu kompiuteriu pajègumu.

Pateiktas metodas, igalinantis surasti branduolio hamiltoniano energijos spektrą, išvengiant superdidelių matricu diagonalizavimo. Metodas paremtas detalia hamiltoniano matricos struktūros analize, jo tikslumas patikrintas ir palygintas su ankstesniu keturiu nukleonų sistemos skaičiavimų rezultatais. 